\title{
Galectin-3: A New Target for Tumor Immunotherapy
}

\section{Yuefei Yu*}

Division of Hematology \& Oncology, Department of Internal Medicine, Texas Tech University Health Sciences Center, Lubbock, Texas, USA

Galectins are a family of lectins which include 15 members and are characterized by a galactose-specific carbohydrate recognition domain (CRD), with an affinity for beta-galactosides. A characteristic of galectins is to mediate recognition of $\mathrm{N}$-acetyl-lactosamine-containing glycoproteins located at the cell surface and within the extracellular matrix. The function of galectins in modulating the immune system and regulating cell growth has been well documented. Galectins are known to carry out intra- and extracellular functions, including inhibition of chronic inflammations, angiogenesis, immune response and cancer cell migration.

Galectin-3, the only chimeric galectin in mammals, consists of three structural domains, N-terminal domain necessary for homodimerization, a C-terminal domain containing a single carbohydrate recognition domain (CRD), and a collagen-like sequence linking the N-terminal domain to the CRD. Galectin-3 involves in neoplastic transformation, angiogenesis, cancer immune evasion, metastasis, invasion and apoptosis [1,2]. Wei et al. [3] showed that the cancer-initiating cells inhibited $\mathrm{T}$-cell proliferation and activation, induced regulatory $\mathrm{T}$ cells, and triggered $\mathrm{T}$-cell apoptosis that was mediated by soluble Galectin-3. Hence, the secretion of Galectin-3 seems to be a feature of nonterminally differentiated cells, which can be reduced along with the immunosuppressive properties, on altering the differentiation state [3]. Ocklenburg et al. [4] provided key information that high levels of Galectin-3 are expressed only in human $\mathrm{CD} 44^{+} \mathrm{CD} 25^{\text {hi }}$ regulatory T cells (Tregs) and FOXP3-transduced Th cells. This analysis indicated that Galectin-3 expression represent a FOXP3-signature of human antigen-stimulated $\mathrm{CD} 4{ }^{+} \mathrm{CD} 25^{\text {hi }}$ derived T-cells (Tregs).

Galectin-3 has been shown to induce the apoptosis of $\mathrm{T}$ cells, including Th1 and Th 2 cells. Additionally, the receptors, N-glycosylated and O-glycosylated, recognized by galectin-3 on T-cell surfaces have been identified. Galectin-3 binding to T cell receptor (TCR) leads to distance TCR from CD8, and decrease cytolytic T lymphocyte (CTL) effector activity. Moreover, Galectin-3 ligands N-acetyllactosamine (LacNAc), can restore effector functions and TCR-CD8 colocalization [5]. Several studies have reported that extracellular Galectin-3 in tumors promotes immune evasion, by inducing apoptosis of CD4 or CD8 T cells in the tumors. The results from the Peng et al. [6] study suggested that extracellular galectin-3 had a negative influence on tumor killing by tumor-reactive T cells. Galectin- 3 could impair the IFN- $\gamma$ secretion of human CD8+ tumor-infiltrating T lymphocytes (TIL). Demotte et al. [7] described that CD8+ TIL treated with an anti-galectin-3 antibody had an effect of increased IFN- $\gamma$ secretion. Interestingly, LacNAc also restored the IFN- $\gamma$ secretion of human CD8+ TIL. On the other hand, GCS-100, a particular modified citrus pectin, detached Galectin-3 from TIL, and led to tumor rejection in tumor-bearing mice vaccinated with a tumor antigen. These results suggest that a combination of Galectin-3 ligands and therapeutic vaccination may induce more tumor regressions in cancer patients, than vaccination alone [7]. GCS100 has been advanced into clinical trials. Thus, treating CD8 TIL with Galectin-3 ligands could boost their cytotoxicity to an efficiency level, and also increase the secretion of cytokines by either CD8 or CD4 TIL including IFN- $\gamma$, IL-2 and TNF- $\alpha$.

Recent investigations of human bonemarrow-derived mesenchymal stem cells (MSC) demonstrated a new role of Galectin-3 in the immunomodulatory function of MSC. The immunosuppressive effect of MSC on lymphocytes could be reduced by knockdown of Galectin-3 in MSC, using small interfering RNA (siRNA) [8]. In another recent study, it was described that DC-expressed Galectin-3 could increase the TCR activation threshold, and act as a negative regulator of $\mathrm{T}$ cell activation [9]. Furthermore, siRNA targeting Galectin-3 modified the function of DCs and enhanced T cell proliferation and IFN- $\gamma$ production. These findings suggest a novel strategy for enhancing $\mathrm{T}$ cell activation in cancer patients.

There are multiple Galectin-3 dependent cancers that may be amenable to therapies targeted at Galectin-3. It is now time for efforts to shift from academic descriptions and experiments into pharmaceutical development. As part of this effort, the current therapeutic agents need to be elucidated the molecular basis of action.

\section{References}

1. Haudek KC, Spronk KJ, Voss PG, Patterson RJ, Wang JL, et al. (2010) Dynamics of galectin-3 in the nucleus and cytoplasm. Biochim Biophys Acta 1800: 181-189.

2. Yang RY, Hsu DK, Liu FT (1996) Expression of galectin-3 modulates T-cell growth and apoptosis. Proc Natl Acad Sci U S A 93: 6737-6742.

3. Wei J, Barr J, Kong LY, Wang Y, Wu A, et al. (2010) Glioma-Associated CancerInitiating Cells Induce Immunosuppression. Clin Cancer Res 16: 461-473.

4. Ocklenburg F, Moharregh-Khiabani D, Geffers R, Janke V, Pfoertner S, et al. (2006) UBD, a downstream element of FOXP3, allows the identification of LGALS3, a new marker of human regulatory T cells. Lab Invest 86: 724-737.

5. Demotte N, Stroobant V, Courtoy PJ, Van Der Smissen P, Colau D, et al. (2008) Restoring the Association of the T Cell Receptor with CD8 Reverses Anergy in Human Tumor-Infiltrating Lymphocytes. Immunity 28: 414-424.

6. Peng W, Wang HY, Miyahara Y, Peng G, Wang RF (2008) Tumor-associated galectin-3 modulates the function of tumor-reactive $T$ cells. Cancer Res 68: 7228-7236.

7. Demotte N, Wieërs G, Van Der Smissen P, Moser M, Schmidt C, et al. (2010) A galectin-3 ligand corrects the impaired function of human cd4 and cd8 tumorinfiltrating lymphocytes and favors tumor rejection in mice. Cancer Res 70 : 7476-7488.

8. Sioud M, Mobergslien A, Boudabous A, Fløisand Y (2010) Evidence for the Involvement of Galectin-3 in Mesenchymal Stem Cell Suppression of Allogeneic T-Cell Proliferation. Scand J Immunol 71: 267-274.

9. Mobergslien A, Sioud M (2012) Galectin-1 and -3 gene silencing in immature and mature dendritic cells enhances $T$ cell activation and interferon- $Y$ production. J Leukoc Biol 91: 461-467.

*Corresponding author: Yuefei Yu, Division of Hematology \& Oncology, Department of Internal Medicine, Texas Tech University Health Sciences Center, Lubbock, Texas, USA, Tel: 806-559-9076; E-mail: yuefei.yu@ttuhsc.edu

Received October 15, 2012; Accepted October 16, 2012; Published October 18, 2012

Citation: Yu Y (2013) Galectin-3: A New Target for Tumor Immunotherapy. Single Cell Biol 2: e116. doi:10.4172/2168-9431.1000e116

Copyright: (c) $2013 \mathrm{Yu}$ Y. This is an open-access article distributed under the terms of the Creative Commons Attribution License, which permits unrestricted use, distribution, and reproduction in any medium, provided the original author and source are credited. 